\title{
Built Heritage and Development: Heritage Impact Assessment of Change in Asia
}

\author{
Ayesha Pamela Rogers \\ Cultural Studies Department, National College of Arts, Lahore, Pakistan \\ Email: culturalheritagenca@gmail.com
}

\begin{abstract}
Built heritage faces increasing pressures and threats from development and change in the contemporary world, a situation that frequently results in compromise or loss of historic fabric and its associated values. This paper examines how Heritage Impact Assessment (HIA) methodology specifically addresses and mitigates threats to built heritage within an overall sustainable development framework. The methodology will be explained and examples will be given from across Asia of HIA applications to the urban and rural built environment to illustrate how this can be achieved. These case studies reflect a variety of ways in which development and heritage come into conflict and have been selected to show how versatile and adaptable HIA can be as a tool for finding balance and solutions. HIA is an approach rooted in a balanced and sustainable relationship between 'the needs of the present and future generations and the legacy from the past' (UNESCO 2011). The paper also illuminates some of the basic assumptions on which HIA functions and some of the contradictions that often arise when the methodology is applied to real world problems.
\end{abstract}

KEYWORDS built heritage, Heritage Impact Assessment, culture, sustainability, development

Received March 25, 2017; accepted June 23, 2017.

\section{Introduction: Built Heritage and Development}

Built heritage faces increasing pressures and threats from development and change in the contemporary world, a global situation that frequently results in compromise or loss of historic fabric and its associated values. This applies equally to individual historic buildings, assemblages and historic areas of towns and cities. A conflict frequently arises between heritage and development, the past and the future; different stakeholders and players in the conservation and development processes take up opposing positions and seem unable or unwilling to find common ground.

The results of this conflict can be damaging on a number of levels, from the loss of historic fabric to impacts on community and social values and the failure to take advantage of economic and developmental opportunities. All of this contradicts the vision of culture as an essential component of sustainable development and heritage as a powerful contributor to economic and social development.
This vision is clearly encompassed in the UN Sustainable Development Goals which state that 'Culture is who we are and what shapes our identity. Culture contributes to poverty reduction and paves the way for a humancentred, inclusive and equitable development. No development can be sustainable without it. Placing culture at the heart of development policies constitutes an essential investment in the world's future and a pre-condition to successful globalisation processes that take into account the principle of cultural diversity.' (UNESCO 2016: 2) The UNESCO World Heritage Committee has acted on this through the adoption of the Policy on the Integration of a Sustainable Development Perspective into the Processes of the World Heritage Convention (2015), confirming the support of the international heritage community for the spirit and letter of the Sustainable Development Goals.

Similarly, Historic England sees the historic built environment as 'a huge resource which can stimulate regeneration and growth in towns, cities and rural areas' (Historic England n.d.). Heritage makes a significant contribution to the UK economy, plays a key role in broader economic 
activity and helps achieve sustainable growth. Similarly, Historic Places Canada maintains that sustainable development 'holds environmental, social and economic benefits for everyone. Heritage conservation responds to these benefits by rehabilitating heritage buildings, a practice that reduces waste and conserves energy. This approach also conserved important non-renewable resources' (Canada's Historic Places 2007).

Conflict arises when the value of the built historic environment is ignored or overridden in the development process. This happens for any number of reasons: competition for space and land values, opposing ideas over the use of space, or a failure to appreciate the creative reuse potential of historic structures and places. In all such cases, opportunities for holistic and sustainable development are lost.

Previously, culture was often understood as a barrier to development and something to overcome, but, gradually, positive connections between culture and sustainable development have become a part of global discourses. Culture is becoming recognised in principle as a cross-cutting issue in local/urban sustainable development.

The challenge lies in how best to operationalise roles for culture within the context of sustainable urban development policy and planning. The relationship between culture and sustainable development is not thoroughly understood, and the integration of culture within broader holistic urban planning and development continues to be an issue due to both conceptual and operational issues (Duxbury et al. 2016). What is needed are tools for integrating heritage into the processes of development and change.

\section{Heritage Impact Assessment: Aims and Process}

Jon Hawkes in 2001 recommended an important move forward to address this need for a mode of operationalisation. Hawkes believes that the notion of sustainability and, more broadly, visions of the future are strongly informed by cultural values: 'In its simplest form, the concept of sustainability embodies a desire that future generations inherit a world at least as bountiful as the one we inhabit. However, how to get there...will always be the subject of constant debate. This debate is about values; it is a cultural debate.' (Hawkes 2001) Moreover, he expressed his concerns about the negative impact that development policies may have on the cultural vitality of society and suggested the establishment of cultural impact assessment tools which would prevent the loss of valuable cultural identities, capacities and resources. Heritage Impact Assessment (HIA) meets this need.
UNESCO and the World Heritage Centre, ICCROM and ICOMOS, the International Association of Impact Assessment (IAIA) and international development agencies such as the World Bank have all endorsed the implementation of HIA as a conservation and management tool in a wide variety of culture and development scenarios, from World Heritage properties to historic towns and individual buildings and cultural landscapes. The potential of the HIA process is explicit, for example, in the Recommendation for the Historic Urban Landscape which states that HUL 'addresses the need to better integrate and frame urban heritage conservation strategies within the larger goals of overall sustainable development', by placing heritage and its management into the larger planning and development framework. The Recommendation identifies a range of tools to achieve this end, including knowledge and planning tools for the monitoring and management of change. Foremost among these tools is HIA which 'should be used to support sustainability and continuity in planning and design' (UNESCO 2011).

HIA is a planning tool that provides decision makers with an understanding of the potential effects that human actions may have on the cultural heritage environment. HIA methodology is 'a process of identifying, predicting, evaluating and communicating the probable effects of a current or proposed development policy or action on the cultural life, institutions and resources of communities, then integrating the findings and conclusions into the planning and decision making process, with a view to mitigating adverse impacts and enhancing positive outcomes' (Sagnia 2004). It serves as a valuable tool for managing change in historic resources by identifying threats to heritage significance and recommending solutions. It does this by considering, weighing and cross-assessing multiple relevant components (Figure 1).

The process of HIA flows through a series of five sequential steps, adaptable for individual cases but fundamentally adhered to. This is the 'consensus methodology for Asia' being developed and refined by WHITRAPShanghai, ICCROM, Asian Academy for Heritage Management (AAHM) and the University of Hong Kong. The 'consensus methodology' was developed by practitioners in commercial HIA, academic researchers in HIA and stakeholders representing relevant government departments and agencies including UNESCO and ICOMOS and international funders such as the World Bank. It is followed by a growing number of HIA practitioners throughout Asia as the result of more than a decade of training and development (http://asian-academy.org/hia-online-manual/). As a result of this process, Asia has played an important role in 


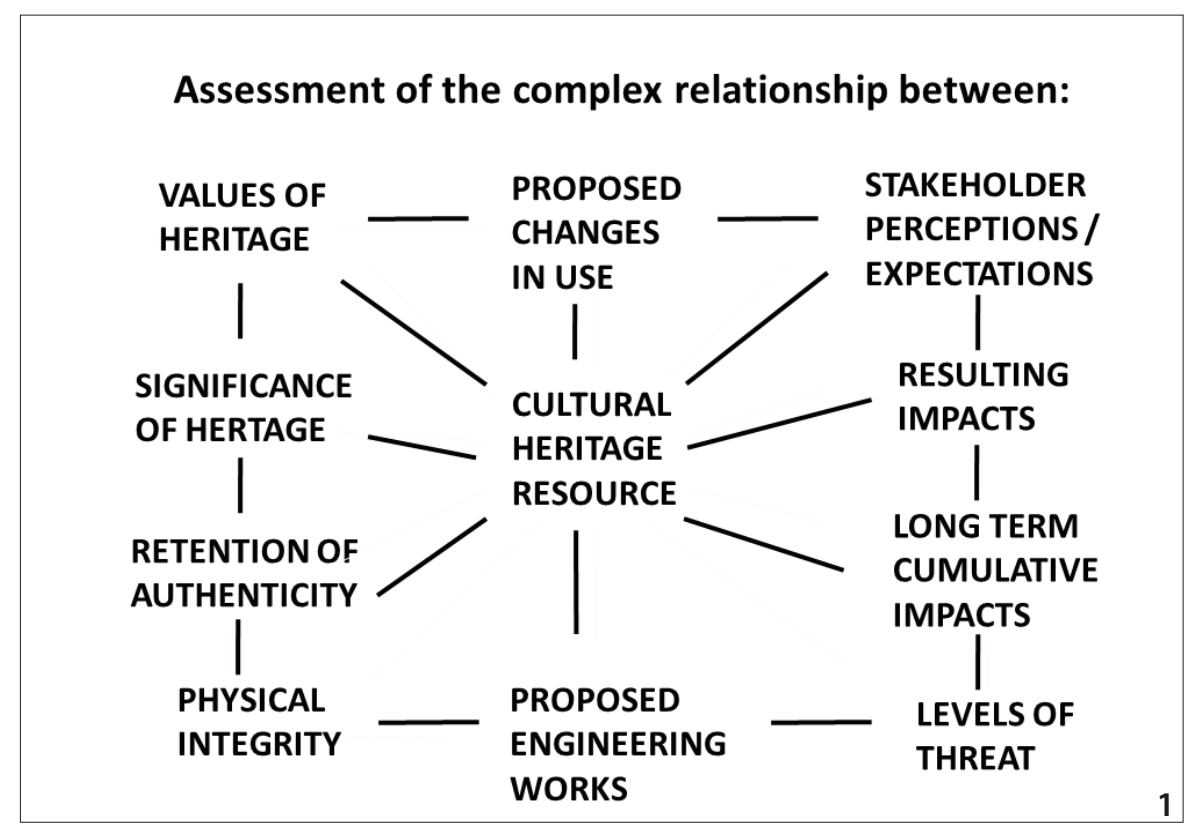

Figure 1 Heritage Impact Assessment (HIA) considers, weighs and cross-assesses multiple relevant components to identify and understand potential impacts of the values of heritage properties (Source: the author).

\begin{tabular}{|c|c|c|}
\hline \multirow{7}{*}{ 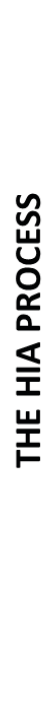 } & \multirow{2}{*}{$\begin{array}{c}\text { Screening \& Scoping } \\
\text { Commissioning } \\
\downarrow \\
\text { Desk-based Study }\end{array}$} & $\begin{array}{l}\text { Identifying need / Defining study / } \\
\text { Appointing practitioners }\end{array}$ \\
\hline & & $\begin{array}{l}\text { Collecting data to establish existing } \\
\text { conditions }\end{array}$ \\
\hline & $\begin{array}{l}\text { Significance Evaluation } \\
\text { Threat Identification } \\
\text { Impact Assessment }\end{array}$ & $\begin{array}{l}\text { What needs protection / Where } \\
\text { threats come from / Nature and } \\
\text { extent of threats }\end{array}$ \\
\hline & $\begin{array}{l}\text { Modelling/Evaluation of Options } \\
\text { Mitigation and Monitoring Plan - }\end{array}$ & $\begin{array}{l}\text { Scenarios for action / Mitigating } \\
\text { impacts }\end{array}$ \\
\hline & \multirow{3}{*}{$\begin{array}{c}\text { Report / Review/ Approval } \\
\downarrow \\
\text { Mitigation Monitoring } \\
\text { Monitoring Report } \\
\text { Archiving of HIA }\end{array}$} & Formalizing compromise \\
\hline & & Ensuring compliance \\
\hline & & Providing public record \\
\hline
\end{tabular}

Figure 2 Flow chart of the HIA process 2 (Source: the author).

furthering HIA process, practice and theory building. The methodology in brief (Figure 2):

1. Scanning, Scoping and Commissioning-to identify the need for an HIA, to define its study area and broad scope and arrange the commissioning by the heritage authority of appropriate practitioners to implement it. This is the critical stage that ensures that no potentially damaging development proposal escapes the impact assessment process.

2. Baseline Documentation-involves collecting and collating data required for a comprehensive understanding of the current or baseline situation; the type, number and distribution of heritage resources as revealed through both desk-based study and additional data acquisition such as community-based mapping needed to fill in any gaps in the database or to expand it where needed. This includes a description of all existing impacts within the study area. The aim is to provide a preproject baseline against which monitoring results can be compared.

3. Evaluating Significance-this may already be known if the heritage is a World Heritage property. Otherwise it requires implementation of cultural mapping to define significance and identify the physical attributes of a property that embodies the property's heritage value(s). Unless the heritage significance of a potentially impacted property is defined and its outstanding values associated with specific physical attributes of the site, an HIA has no basis or measure on which to make the judgments.

4. Threat Analysis-identification of where impacts may come from, what type they might be and how 


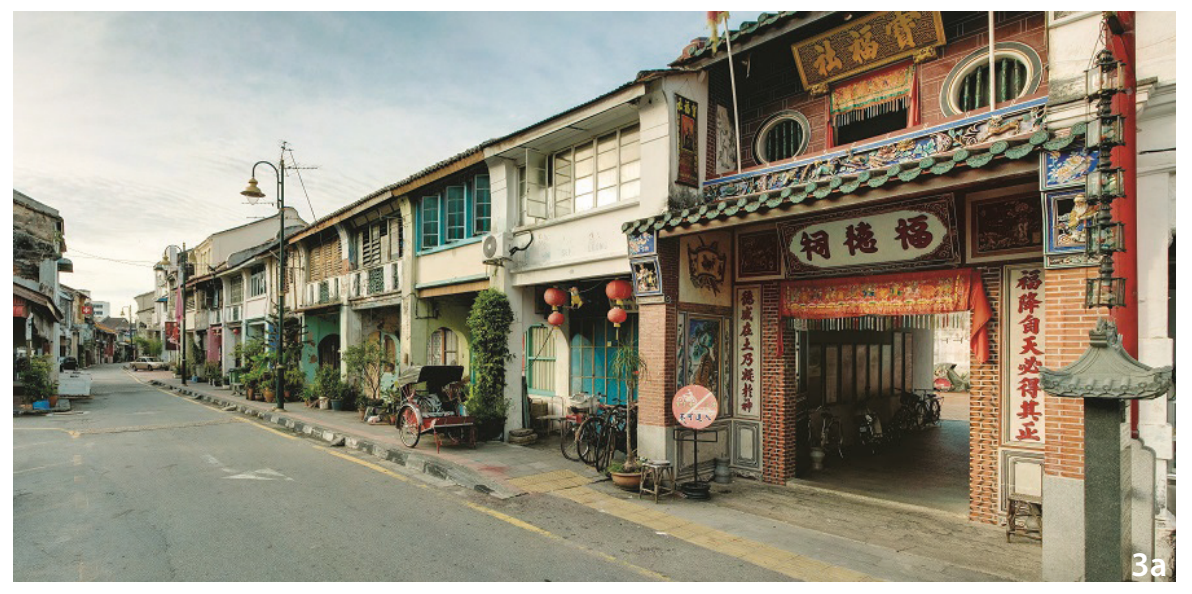

Figure 3a Shop-houses and the built environment that characterises the World Heritage property of Melaka and George Town: Historic Cities of the Straits of Malacca (Source: the author).

permanent they may be, using matrices for systematic cross-tabulation of all components of proposals with the identified and potential heritage resources and their significance-bearing attributes.

5. Assessment of Impacts-determination of the degree of impacts by combining the identified threats with an assessment of the severity of predicted impacts, a factor of the type, reversibility and duration and spatial extent of impacts. Use of an Impact Matrix tells us the scale of each impact in relation to the significance of the heritage resource. This is then evaluated in terms of acceptability and the resulting need for mitigation measures.

6. Mitigation and Monitoring-design of a mitigation strategy to identify ways of 'avoiding the impact by not taking, or modifying an action; minimizing, rectifying or reducing the impacts through the design or operation of the project/policy; or compensating for the impact by providing substitute facilities, resources or opportunities' (Sagnia 2004). This involves public participation to get stakeholder input and feedback into the Mitigation strategy. It is followed by licensing, final approval of the HIA of the Authority and Compliance Monitoring as a follow-up program to ensure that Mitigation is carried out as designed.

7. Reporting - full reporting on all stages of the HIA, including all data and analysis, is prepared, submitted to the client and relevant authorities and made available for public review and comment.

Throughout the HIA process consultation with and the participation of a wide range of community stakeholders are critical. This is particularly important in identifying what comprises heritage in the individual and shared visions of local residents, the understanding of its significance and identification and assessment of threats to heritage.

The HIA process also makes some basic assumptions about both development and heritage, in particular, built heritage. The idea that the proponents of change are understanding, if not sympathetic to the values of built heritage to communities underlies HIA thinking, as does the belief that proposed developments are amenable to compromise and modification for the good of heritage. At the same time, HIA assumes that the historic built environment can add benefits or added value to developmentto make it sustainable - and that it can and should absorb some degree of compromise in order to achieve this.

To better understand the process and application of HIA we will examine several projects, all focused on built heritage but of very different types, in different countries under varying HIA regimens. The first investigates impacts of birds nest farming on outstanding universal values of vernacular urban architecture in the World Heritage property of Melaka and Penang, Malaysia; the second assesses potential impacts of a proposed theme park development on a major Mughal monument in Lahore, Pakistan; and the third looks at potential impacts of a proposed adaptive re-use project, under a government-sponsored partnership scheme, for a vernacular residential property in Kowloon, Hong Kong.

\section{HIA for Safeguarding Heritage against Existing Threats. The Swiftlet Industry in Melaka and George Town: Historic Cities of the Straits of Malacca}

The Historic Cities of the Straits of Melaka are inscribed on the World Heritage list under criteria (ii), (iii) and (iv) as:

remarkable examples of historic colonial towns on the Straits of Malacca that demonstrate a succession of historical and cultural influences arising from their former function as trading ports linking East and West. These are the most complete surviving historic city 


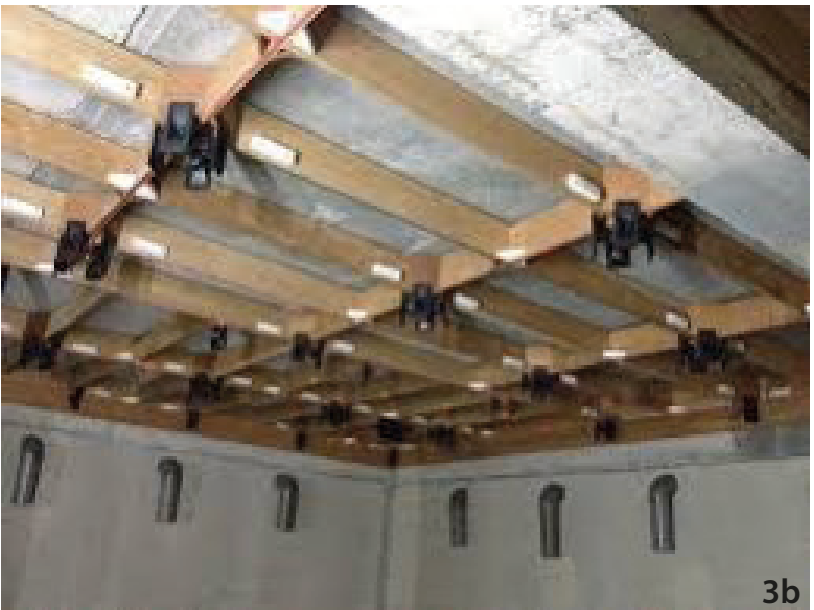

Figure $\mathbf{3 b}$ View of alterations and environmental changes made to historic shop-houses for use as swiftlet farms (Source: Archaeological Assessments Ltd.).

centres on the Straits of Malacca with a multi-cultural living heritage originating from the trade routes from Great Britain and Europe through the Middle East, the Indian subcontinent and the Malay Archipelago to China. Both towns bear testimony to a living multicultural heritage and tradition of Asia, where the many religions and cultures met and coexisted. They reflect the coming together of cultural elements from the Malay Archipelago, India and China with those of Europe, to create a unique architecture, culture and townscape (http://whc.unesco.org/en/list/1223).

Swiftlet farming in Malaysia is not a traditional agricultural practice, but rather a much more recent phenomenon. In the 1990s, edible birds nest farmers began to use intensive methods for the attraction of the birds to houses, most notably to historic shop-houses inside the historic centre (Figure 3a). The ideal habitat conditions for breeding require warm temperatures, high humidity, lack of air movement and relative darkness. These conditions are met by sealing the abandoned historic shop-houses, removing or concealing interior features, introducing moisture and heat and restricting light and ventilation.

The bird's nest industry is extremely lucrative, and although the Malaysian government has attempted to control it with legislation and licensing procedures, the practice is expanding and affected increasing numbers of protected historic properties within the World Heritage property. As many as 160 known properties were documented.

An HIA was commissioned by the Malaysian Government in 2011 at the request of the Director of the World Heritage Centre. The aims of the HIA were to establish both the background and history of the swiftlet industry in the two historic cities as well as the background of the shop-house buildings that have been converted to this use and the surrounding neighbourhoods. In addition to deskbased research, an assessment visit was an important step in the process, as this allowed first-hand information on the condition of the buildings being utilised or formerly utilised as swiftlet houses and also the alterations that had been undertaken to create an environment that is conducive to the new function. Local residents and their organisations opposed to the industry, swiftlet farmers and their organisations were consulted and their conflicting opinions and versions of the 'facts' were recorded. All the above information was collated to identify the aspects of the World Heritage Site which may be affected by the swiftlet farms, including negative impacts on the overall quality of the heritage buildings and the effect on the physical fabric of the buildings and/or the heritage townscape.

The assessment was based on international best practice as presented in the ICOMOS Guidance on Heritage Impact Assessments for Cultural World Heritage Properties (2011). It focused on impacts on historic shop-houses during two phases: alteration of the buildings for use as swiftlet farms and impacts resulting from that use. Using assessment matrices, it looked closely at elements of special interest that reflect the values and authenticity of the built type include their layout, traditional building fabric, courtyards, roofing style and the structural and decorative elements that define shop-house styles. Guidelines and Principles stated in the Conservation Management Plan and Special Area Plan were used to evaluate the impacts seen on these elements of special interest (Cameron et al. 2012).

The alterations and additions that are undertaken during the conversion process are not in accordance with the Conservation Management Plan and Special Area Plan in that they do not respect the character of the shop-houses and the works carried out damage or destroy traditional architectural elements. Additionally, the damage to traditional building fabric of the shophouses has been shown to be extensive and very difficult and costly to reverse, making restoration of the shop-house to its pre-swiftlet farm traditional form an expensive and technically complex procedure. It has also been shown that the day-to-day operational practices of the swiftlet farm damage or destroy the authenticity of the shop-houses through ongoing and increasing structural damage and degradation of building fabrics (Cameron et al 2012) (Figure 3b). 


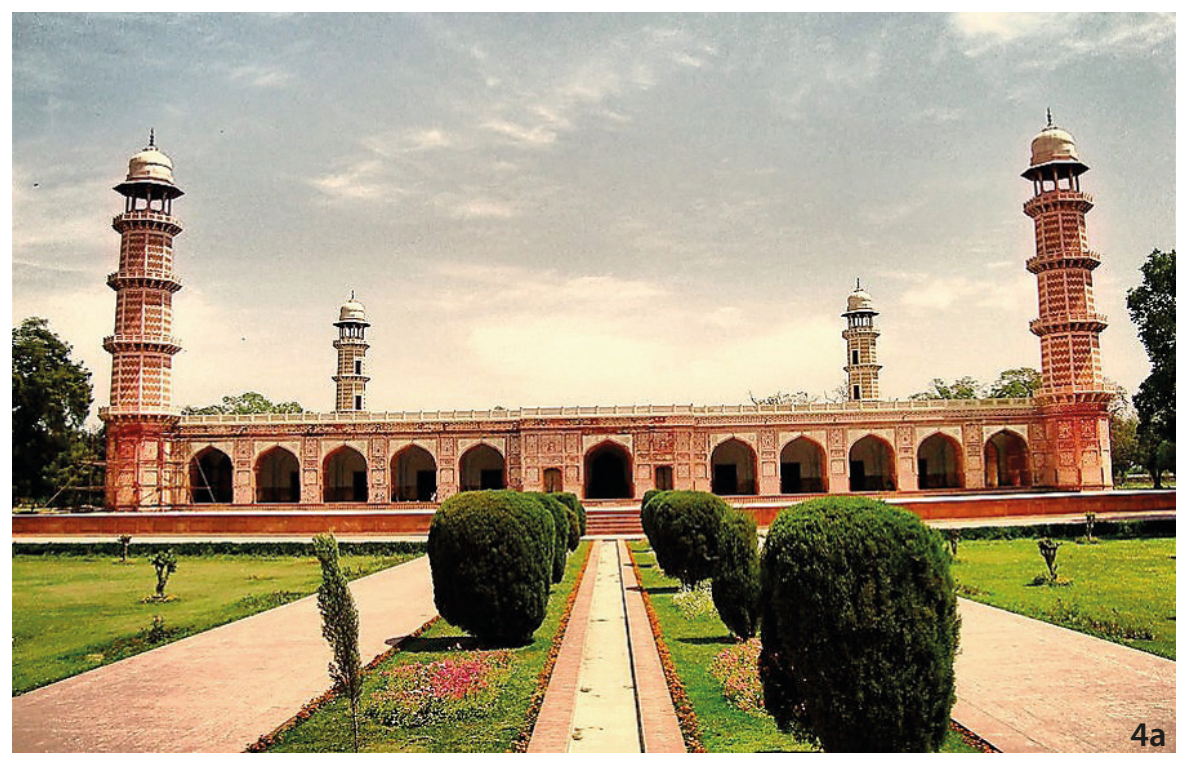

Figure 4a View of the Jahangir's Tomb, part of the World Heritage Tentative List property at Shahdara, Lahore (Source: the author).

Both aspects, conversion and operation, were identified as unacceptable by the HIA process. It was therefore considered essential that no new farm conversions in shophouses be allowed and that existing farms be forced to cease operation in line with government requirements and the action plans of the local authorities to stop the ongoing damage to these buildings.

It was also a finding of the HIA that swiftlet farm operators were using delaying tactics to allow for the profitable enterprise of swiftlet farming to continue as long as possible but with the knowledge that removal of the swiftlet premises inside the World Heritage property was inevitable. 'The prevarication and procrastination of the swiftlet farm operations only made a bad situation worse and could have led to so drastic an action that World Heritage listing may come in question and the property inscribed on the List of World Heritage in Danger.' (Cameron et al 2012)

The HIA found that application of thorough and comprehensive HIA methodology revealed

the overwhelming unacceptability of the current de facto state of practice which accepts swiftlet farming within the buildings situated within the World Heritage property in both Melaka and George Town. The practice of swiftlet farming has already compromised the authenticity and integrity of the character-defining attributes of each of the criteria for which these properties have been inscribed on the World Heritage list. The overall result of this compromising practice constitutes a measurable loss of heritage fabric and cultural significance. The longer the practice-which is illegal in the context of Malaysian law-is allowed to continue, the greater will be the cumulative negative impacts and the more difficult, time-consuming and costly these impacts will be to reverse. Compromising the value of World Heritage properties, swiftlet farming in Melaka and George Town is a practice which expropriates public values for private profit, the long-term burden of which will be borne by the Malaysian public (Cameron et al. 2012).

\section{HIA for Safeguarding Heritage from Potential Threats: Preliminary Concept Plans for the Shahi Bagh Project, Lahore}

The proposed Shahi Bagh Project entails development of a modern theme park and water park, which also includes restoration of five heritage buildings namely Jahangir Tomb (1637), Asif Khan Tomb (1641), Akbari Sarai, Noor Jahan Tomb (1645) and Baradari of Kamran Mirza (1527). The Shahdarah monuments incorporate an important range of sites which together tell a valuable and integrated story about the Mughal funerary gardens of Lahore in the $16^{\text {th }}$ and $17^{\text {th }}$ centuries (Figure $4 \mathrm{a}$ ).

All the monuments have individual provincial and national legal protection and the tombs of Jahangir and Asif Khan with the Akbari Serai are on Pakistan's UNESCO World Heritage Tentative List. The Shahdara monuments are located on the north bank of the Ravi River approximately $3.7 \mathrm{~km}$ north northwest of the historic Walled City of Lahore. The monuments stand on the alluvial flood plain of the Ravi which has changed its course substantially over the centuries. The integrity of the Shahdara 




Figure 4b Plan for the proposed Shahi Bagh Mughal Theme Park at Shahdara, Lahore (Source: Lahore Development Authority, Pakistan). complex as a whole has been impacted by flooding of the Ravi on numerous occasions and the shifts in the river's alignment. Similarly, truncation and division of the complex by the North Western Railway line and the loss of buffer zone and the pressing in of modern construction against its walls on several sides. Despite this, the spirit and feeling maintained in the complex despite contemporary pressures and intrusions explain how each of the individual monuments and heritage resources contributes to the overall significance of the Shahdara Monuments Complex (Rogers Kolachi Khan 2011).

The proponents of the Shahi Bagh project aim 'iii. To promote the heritage, Islamic culture and Mughal Architecture, and enrich the gateway of Lahore as a cultural heritage cum regional entertainment hub' (LDA 2014). The Shahi Bagh project will be developed as an amalgamation of culture and modern recreation, wherein the heritage area will be on one end and the modern entertainment such as hotel, restaurants, aquarium and cineplex on the other. The project includes the development of an entertainment sector in the eastern portion of the site, a minimum of $3 \mathrm{~km}$ from the eastern end of the heritage complex, with park area including an artificial water body and canals in a forested, landscaped zone which will extend to and surround the main monument complex. Access to the park from the entrance in the west to the eastern area will be via walking trails and a proposed tram running inside the periphery wall of the site. The heritage buildings are envisioned as an integral part of the park and their conservation, maintenance and interpretation are intended to form part of the overall project strategy (LDA 2014) (Figure 4b).

The HIA addressed the potential impacts and issues which may arise from the proposed Shahi Bagh Project on the archaeological heritage within the project area, with a particular focus on potential unacceptable impacts on the heritage values and authenticity of the UNESCO World Heritage Tentative List property that could result from visual and aesthetic encroachment and over-commercialization from the proposed theme park entertainment facilities.

It is important to note that this HIA was preliminary in nature as it was based on the current Stage 1 'broadbrush' concept plan for the Shahi Bagh Mughal-themed entertainment district rather than on detailed engineering works and development proposals. The Shahi Bagh Project in its preliminary stages had taken on board the need for assessment of possible impacts on the Shahdara Mughal monuments which are, after all, the cornerstone of the development. The HIA did not include public input or community consultation due to the confidential and preliminary nature of the project plans.

The HIA identified a number of beneficial impacts that could result from the project, in particular: the commitment to carry out on-going conservation and management of the monuments and site; plans for reinstatement of the original Mughal period waterworks system; the flood protection that would accrue from river training 
works; the improvements in the local setting as a result of land acquisition and landscaping plans; and reinforcement of the original group statement of the monuments (Rogers Kolachi Khan 2014).

There were a number of interventions proposed which were assessed as acceptable only with mitigation to safeguard the fabric, setting and values of heritage resources. These included major engineering works and construction, changes to the overall environment and the introduction of new uses or activities in or near the monuments. The predicted results would be a large scale increase in visitor numbers; the threat of visual intrusions into the World Heritage property from features of the theme park; and, above all, risk to the authenticity of the Mughal heritage as a result of commercialization and 'de-contextualisation' or falsification of the real values of the heritage resources.

A mitigation strategy was recommended by the HIA based on the findings of the assessment which stressed the importance of zoning to help separate the new tourism and entertainment venues and features from the heritage resources and to control where various activities are acceptable or unacceptable. Monitoring of potential impacts of moisture and vibration on built fabric, archaeological monitoring of construction works, temporary protection of buildings during engineering and construction works and commissioning of a comprehensive Conservation and Tourism Management Plan formed the basis of mitigation. A critical recommendation was that further HIAs would need to be carried out as the design process evolves and detailed plans and designs are prepared for specific features of the park (Rogers Kolachi Khan 2014).

In summary, the findings of the HIA of the preliminary concept plan for Shahi Bagh combined in overall favour of the proposed project. The project could feasibly offer benefits and added value to the heritage site through the implementation of the Mitigation Strategy proposed by the HIA combined with an overall sympathetic approach to combining heritage and tourism development.

\section{HIA for Safeguarding Heritage by Ensuring Its Life in the Community: Revitalisation of the Stone Houses at Junction Road, Kowloon City into Stone Houses Family Garden}

The Stone Houses are a block of five Chinese vernacular houses located in the former village of Hau Wong New Temple, now part of modern Kowloon City, Hong Kong. They were built between 1945 and 1947 in the village which dates at least to the early $18^{\text {th }}$ century when the temple of Hau Wong was constructed. The area of the Stone Houses was sparsely occupied the agricultural land until the 1920s when a large Christian cemetery was constructed immediately to the north of the village. During this period, there was an influx of mainland immigrants fleeing China's warlords, while new roads and housing developments grew up around the traditional villages. More resettlement accommodation was constructed in the area at the beginning of the Japanese occupation when many older settlements nearby were razed for the expansion of Kai Tak airport. The density of the area increased again after the war when large numbers of refugees fled civil war in China and were housed in temporary but long term 'cottage areas' clustered around the Stone Houses. This low-rise density continued until 2001 when all the cottages and villages in the area were razed by the Housing Authority for new development, leaving the Stone Houses alone in a small green patch surrounded by roads and high-rises (Ho, Lo \& Lam 2011).

The Stone Houses are a project put forward by a church-related organisation specialising in youth programs and community service as part of the government's Revitalising Historic Buildings Through Partnership Scheme (Hong Kong Legislative Council 2009). The project aims to revitalise the building through adaptive re-use as 'Stone House Family Garden' incorporating a themed cafeteriacum-Visitor Information Centre. The project aimed to restore the building following best practice and to use it to promote understanding among the youth of traditional Hong Kong values and changes in the locality through time. As a public works project involving historic built heritage, in this case, a Grade 3 Historic Building, the authorities required that an HIA be carried out of the proposal (Hong Kong Development Bureau 2009).

The HIA established the significance of the graded building as lying in the traditional design and spatial layout of the structure, the use of granite wall masonry and traditional wood and clay tile roofing, internal use of timber floors, staircases and dividing walls. The houses represent a rural vernacular residential type that characterised Hong Kong until the mid $20^{\text {th }}$ century (Figure 5). The property is also important for its linkages to the historical evolution of this area and Kowloon district (Ho, Lo \& Lam 2011).

A preliminary condition assessment was carried out and found that structural elements of the building were in poor condition but were considered adequate for adaptive re-use with conservation and design limits. The timber roofing and many of the internal timber elements were 




Figure 5 View of the Stone Houses, Kowloon City, Hong Kong before conservation for adaptive reuse (Source: the author).

rotting and needed to be replaced.

The HIA used matrices to analyse the separate actions of the re-use proposal against the affected character-defining elements/fabric, the level of significance of that element and the predicted level of impact. The outcome was a set of action-specific mitigation recommendations (Ho, Lo \& Lam 2011).

The primary focus of the HIA was on impacts that might occur on the physical fabric of the buildings, and it therefore relied on 'expert' input over community opinion. However, the stated primary purpose of the proposed project was to interpret traditional values to the younger generation of Hong Kong. Therefore, the HIA incorporated local input and recommended a theme, the links between the Stone Houses and changes in the locality through time, and proposes a conceptual framework for how each area of the property could be used to tell different stories about this theme along with recommended interpretive tools and outputs.

The HIA highlights the need for detailed architectural documentation of the Stone Houses as a pre-requisite for starting work on the development project. It also sets out requirements or guidelines for conservation standards, an on-going management and maintenance plan, staffing levels and proposes a detailed schedule for project works (Ho, Lo \& Lam 2011).

\section{HIA as a Tool for Managing Change}

These three HIA studies were commissioned under different circumstances and with very different 'agendas' or ends in mind. The World Heritage Centre requested an HIA for the Historic Cities of the Straits of Melaka with the full knowledge that the swiftlet farming was causing irreparable damage to the Outstanding Universal Value (OUV) of the World Heritage property. What they and the Malaysian heritage authorities needed was a convincing and authoritative statement based on a rigorous method that would support their efforts to bring about a total shut-down of the birds' nest industry.

The HIA was submitted to the World Heritage Committee via the Government of Malaysia in 2012; after which most of the remaining swiftlet farming premises were shut down. Consequently, UNESCO later announced in 2013 that they were satisfied with the action taken by the authorities and that the site would consequently not be added to the List of Heritage Sites in Danger.

When the concept plan for Shahi Bagh Mughal Theme Park was put forward by the Punjab Government, it raised immediate concerns for the Department of Archaeology about the potential impacts on a highly valued heritage site. The implications of developing a theme park which incorporates a World Heritage Tentative List property were also not underestimated: in general it is fair to say that a proposal to commercialise heritage and integrate it with entertainment facilities is frowned upon by the World Heritage Committee. The project proponents commissioned an HIA to provide a convincing and authoritative statement based on a rigorous method which they hoped would provide some support for the broad-brush park plan, or at least propose a compromise plan that would be acceptable to all parties.

The HIA was presented to the concerned heritage authorities who accepted its findings and agreed that if the guidelines and mitigation recommended by the HIA were adhered to the Shahi Bagh project would not compromise the heritage values of the Mughal monuments or their authenticity and integrity and that, in fact, it could potentially improve the setting and environment of the monuments, invest financially in their conservation and upgrade the visitor understanding and experience of the heritage. Shahi Bagh theme park project is still on the drawing boards as of 2017, three years after submission of the HIA. Delays are due, in part, to funding and land acquisition issues.

The Hong Kong Government's Revitalising Historic Buildings through Partnership Scheme is an initiative to 


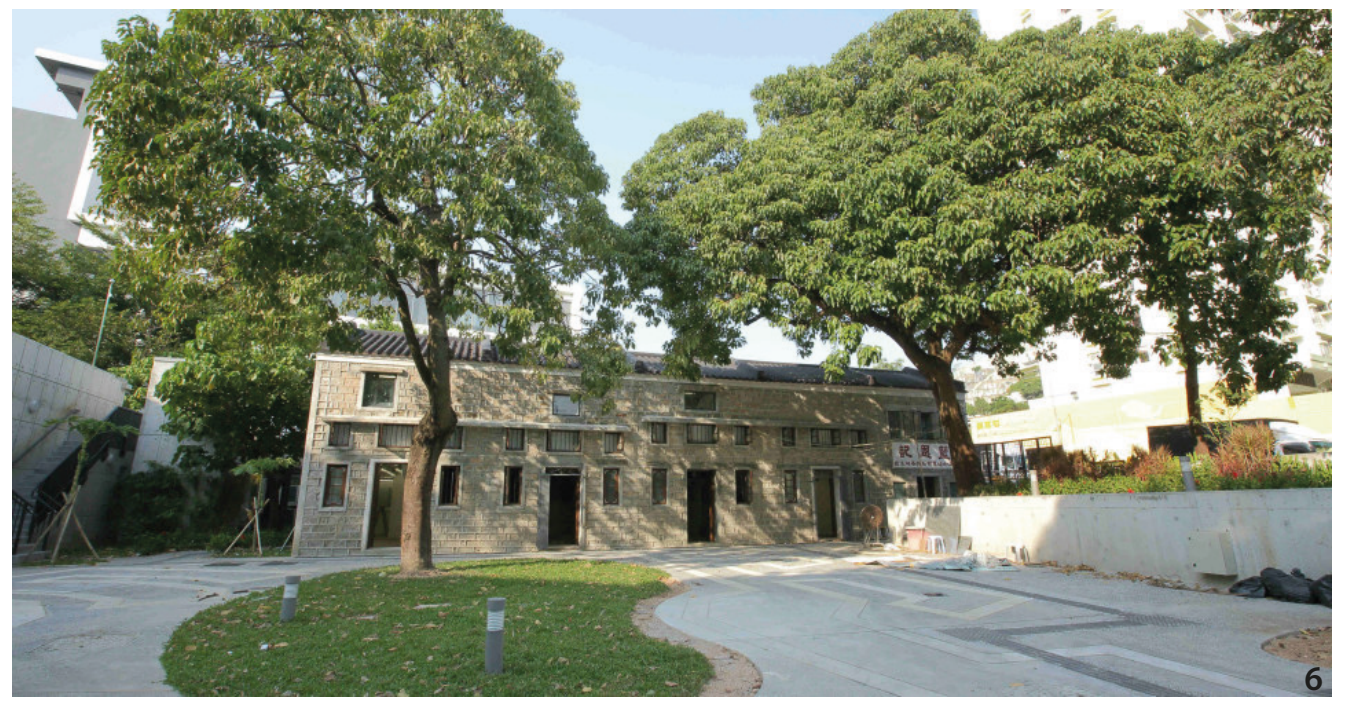

Figure 6 The Stone Houses. Kowloon City, Hong Kong redeveloped as Stone Houses Family Garden (Source: www.stonehouses.org). support private-public schemes for the adaptive reuse of privately owned historic buildings (Hong Kong Legislative Council 2009). All projects must undergo an HIA as part of the application process to ensure that the impacts of the proposal fall within acceptable limits. This is a reflection of the Hong Kong Government's commitment to HIA and their belief in the HIA as an important planning, development and conservation tool. Every year dozens of HIA are carried out for proposals ranging from major infrastructure developments to minor engineering works and conservation and reuse projects. Under the Partnership Scheme many properties have been revitalised and taken on new community use and meaning; the Stone Houses Family Garden was completed in 2015 and now serves the local community and Hong Kong as a café, museum, garden and interpretive centre (Figure 6).

In each of these cases HIA following the 'consensus methodology for Asia' was seen by the commissioning agents as a tool which could be relied upon to present the facts, draw rational and balanced conclusions and support the overall agendas of both heritage conservation and development through mitigation and compromise.

Even the most thorough HIA, however, is of little use if it is not operationalised at the decision making and implementation stages. Decision making rarely proceeds in the detached and unbiased manner intended, where all the information and analysis presented in the HIA is taken into balanced consideration. Often decisions reached depend more upon other underlying interests, 'reflecting the norms and values of decision-makers who are usually operating within a political arena. It is particularly in the later stages of decision making that the findings of HIA are likely to give way to political considerations' (Leknes
2001). As a result, HIAs may not always succeed in achieving its goal of ensuring that heritage considerations are fully incorporated into decision making.

An HIA practitioner may also frequently find herself balancing opposing agendas: an agenda to maintain heritage and the status quo and an opposing agenda for change to achieve public benefit. An example of this is an HIA carried out to assess potential impacts of a mass transit line being built through Lahore, Pakistan, a project generally accepted to be a priority need for the community. The HIA focused on a number of historical buildings in close proximity to the train line (Rogers Kolachi Khan 2016) (Figure 7). It assessed the adverse impacts as acceptable if a comprehensive mitigation program for each building was followed and was of the view that the need for the infrastructure outweighed concerns regarding residual visual impacts. However, the HIA was commissioned late in the development process, even as construction was underway, and community and political objections have placed the project on hold as the case is reviewed by the nation's Supreme Court. The highly charged political context of this HIA has meant that the government client placed restrictions on the consultants which prevented any community consultation.

A second example concerns the proposed construction of an escalator in Pound Lane, a historic 'ladder street' on the steep slope of Hong Kong Island (Figure 8a). The proposed infrastructure was designed to help relieve traffic pressures in the area. Pound Lane is linked with the early history of Chinese immigration and has a number of heritage buildings in its environs. The lane itself comprises significant granite steps, parapets and retaining walls and an important visual corridor down the hill towards Victoria harbour. 



The findings of the HIA report were that in principle the installation of an escalator at Pound Lane can be undertaken without compromising the cultural heritage significance of the area to an unacceptable extent. However, the current design still contains impacts that cannot be adequately mitigated against and further investigation of design options for the escalator and possible removal of the elevated walkway must be included in the detailed design to ensure the overall acceptability of the project' (Archaeological Assessment 2014) (Figure 8b). The proposals and the HIA were put forward for the first round of public consultation in 2013 but met with opposition on heritage and other grounds, including community concerns about potential change to the overall character of the area. After changes to the project design a new round of public consultation is planned.

These examples illustrate how HIA can provide a way to satisfy both agendas, aiming to achieve benefits for heritage and society alike; but, at the same time, they warn us that there will be times when one or the other definition of 'public benefit' must take precedence, either public benefit residing in heritage conservation or in development.

HIA plays a pivotal role in aligning these 'cultural matters' such as built heritage and elements of the historic built environment with change and development. It achieves this, ideally, because it focuses on the wider heritage setting, integrating natural and cultural attributes, and integrates involvement of the local population from
Figure 7 Photo-montage of the proposed Orange Line elevated rail line in front of Shalamar Gardens World Heritage property (Source: Lahore Development Authority, Pakistan).

Figure 8a View of Pound Lane ladder street in Hong Kong's historic Mid-levels (Source: the author).

Figure $\mathbf{8 b}$ Artists rendition of the proposed escalator in Pound Lane (Source: en.poundlane.hk/project.php).

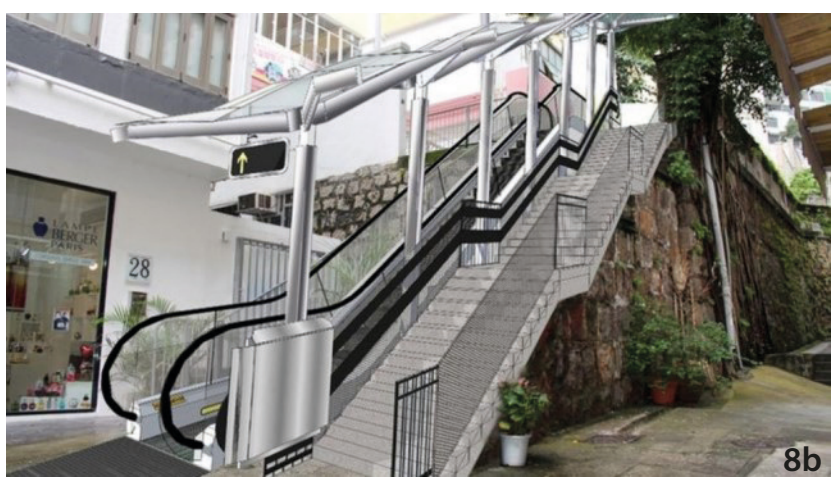

the earliest stage in the assessment to the final proposal of mitigation measures. This, of course, is the ideal scenario envisioned by the 'consensus methodology' but the case studies presented above have shown that the reality for HIA practitioners can be quite different. Restrictions and 'handicaps' can be placed on an HIA by a client including limited access to necessary data, confidentiality clauses, restrictions on public consultation or unrealistic timeframes and scope of works.

This is less likely to occur in places where HIA is a legal requirement and is framed by environmental and heritage legislation and standards. Formation of local or regional organisations for practitioners will also strengthen their position and reinforce the HIA methodology. The result will be that HIA functions not just for protecting built heritage, but can also be used as a vehicle to provide benefits that enhance and improve them.

\section{Conclusions: HIA as a Tool for Sustainability}

The HIA process aims to negotiate sustainable solutions to conflicts between the needs and aspirations of cultural heritage and development. The examples presented in this paper raise some important points regarding the success of HIA in meeting these aims and the prospect for HIA as a critical tool for sustainability.

According to the Brundtland Commission (1987), 
sustainable development is that kind of development that meets the needs of the present without compromising the ability of future generations to meet their own needs. ICOMOS maintains that 'cultural heritage and particularly historic cities and settlements are a reference model for sustainable development' (ICOMOS 2016). This 'reference model' developed from recent thinking on heritage as 'a crucial aspect of the development process' and calls for an integration of culture and heritage into the development agenda where they 'can play a more central role in economic development, poverty reduction and community interaction (ICOMOS 2011). In addition, the Hangzhou Declaration advocates the role of heritage in passing the value and sense of place from generation to generation and as the crucible for creativity' (UNESCO 2013). In the words of Amartya Sen, 'cultural matters are integral parts of the lives we lead. If development can be seen as an enhancement of our living standards, then efforts geared to development can hardly ignore the world of culture' (Duxbury et al 2016).

The contribution of built heritage to sustainability is multi-faceted, and the subject of such seminal studies as those by the World Bank (1994), English Heritage (2013), UNESCO (Bandarin et al 2011), the Getty Conservation Institute (2003) and other relevant bodies. It includes economic benefits from the use and reuse of standing structures, non-use economic value as an investment for future generations, continuity of materials and craftsmanship and the environmental benefits of minimising waste.

Most importantly, conservation and reuse of built heritage allow communities to hold on to the specialness of a place, and the identity and social cohesion this engenders. The UN-Habitat Agenda (2003) states: 'Conservation, rehabilitation and culturally sensitive adaptive reuse of urban, rural and architectural heritage are also in accordance with the sustainable use of natural and human-made resources. Access to culture and the cultural dimension of development is of the utmost importance, and all people should be able to benefit from such access.'

'Sustainability is essentially a means and not an end-it is an attitude and a state of mind through holistic thinking. The application of sustainable development requires that we see the world as a system that connects space as well as time and people. The future of sustainability is to be sought in the integrative approach to culture and development. Sustainability therefore not only relates to time by the transmission and development of culture over generations but also to place' (UNESCO 2016). It is this grounding in the built heritage of specific geographic 'places', the communities that inhabit them and the challenges of temporal change both heritage and communities face, that makes HIA a tool with potential helping to achieve this vision of the future.

\section{References}

Archaeological Assessment. 2014. "Draft Heritage Impact Assessment for Project PL". Unpublished report for Highways Department, Hong Kong.

Asian Academy for Heritage Management (AAHM). HIA Online Manual. Accessed June 23 2017. http://asianacademy.org/hia-online-manual/

Bandarin, Francesco, Jyoti Hosagrahar, and Frances S. Albernaz. 2011. "Why development needs culture", Journal of Cultural Heritage Management and Sustainable Development 1(1): 15-25.

Cameron, E. et al. 2012. "Heritage Impact Assessment on the Swiftlet Industry in Melaka and George Town: Historic Cities of the Straits of Melaka”. Unpublished report for the Government of Malaysia.

Canada's Historic Places. 2007. Sustainable Development. Heritage Conservation Brief.

Duxbury, Nancy, Jyoti Hosagrahar, and Jordi Pascual. 2016. Why Must Culture Be at the Heart of Sustainable Urban Development? United Cities and Local Governments (UCLG).

English Heritage. 2013. Heritage Counts. Accessed June 23 2017. https://historicengland.org.uk/research/heritagecounts/

Hawkes, J. 2001. The Fourth Pillar of Sustainability: Culture's Essential Role in Public Planning. Report for the Cultural Development Network Victoria.

Historic England n,d,. Heritage and Sustainable Growth. Accessed June 23 2017. https://historicengland.org.uk/ advice/planning/heritage-and-growth/

Ho, P. P., K. Y. H. Lo, and S. M. H. Lam. 2011. "Heritage Impact Assessment for Revitalization of the Stone Houses at Junction road, Kowloon City into Stone Houses Family Garden". Unpublished report for the Wing Kwong So Care Company Limited.

Hong Kong Development Bureau. 2009. Heritage Impact Assessment Mechanism for Capital Works Projects. Technical Circular (Works) No. 6/2009.

Hong Kong Legislative Council. 2009. Background Brief on Revitalizing Historic Buildings Through Partnership Scheme. Panel on development.

ICOMOS. 2011. Guidance on Heritage Impact Assessments for Cultural World Heritage Properties.

ICOMOS. 2016. Cultural Heritage, the UN Sustainable Development Goals, and the New Urban Agenda. ICOMOS 
Concept Note for the United Nations Agenda 2030 and the Third United Nations Conference on Housing and Sustainable Urban development (Habitat III).

Leknes, Einar. 2001. "The Role of EIA in the Decisionmaking Process". The Environmental Impact Assessment Review 21: 309-334.

Rogers, Kolachi Khan. 2011. "Site Conservation Assessment Report: Jahangir’s Tomb Complex, Lahore, Pakistan". Unpublished report for Global Heritage Fund.

Rogers, Kolachi Khan. 2014. "Heritage Impact Assessment on Preliminary Concept Plans for Shahi Bagh Project". Unpublished report for Lahore Development Authority Strategic Policy Unit.

Rogers, Kolachi Khan. 2016. "Heritage Impact Assessment of the Lahore Orange Lone Metro Train Project”. Unpublished report for the Lahore Development Authority.

Sagnia, K., Burama. 2004. Framework for Cultural Impact Assessment. International Network for Cultural Diversity: Cultural Impact Assessment Project.

Teutonico, Jeanne, Marie, and Frank, Materoa, eds. 2003. Managing Change: Sustainable Approaches to the Conservation of the Built Environment. Getty Conservation Institute: Los Angeles

UN. 1987. Brundtland Report: Our Common Future. Report of the World Commission on Environment and Development.

UN-Habitat. 2003. Habitat Agenda Goals and Principles. Commitments and the Global Action Plan. Accessed June 23 2017. https://unhabitat.org/wp-content/ uploads/2014/07/The-Habitat-Agenda-Goals-andPrinciples-Commitments-and-the-Global-Plan-ofAction-2003.pdf

UNESCO. 2013. The Hangzhou Declaration: Placing Culture at the Heart of Sustainable Development Policies. Adopted in Hangzhou, People's Republic of China, 17 May 2013.

UNESCO. 2016. Culture Urban Future: Global report on Culture for Sustainable Urban Development. UNESCO: Paris.

UNESCO World Heritage List. Accessed June 232017. http://whc.unesco.org/en/list/1223).

World Bank. (1994). Cultural Heritage in Environmental Assessment. Environmental Assessment Sourcebook Update. Environmental Department, World Bank. 